\title{
Numerical Simulation of Convection in Triangular Cavities to Predict Solar Still Performance
}

Jeremy D. LeFevre

jlefevre76@hotmail.com

W. Jerry Bowman

jbowman@et.byu.edu

Matthew R. Jones

Brigham Young University - Provo, mrjones@byu.edu

Follow this and additional works at: https://scholarsarchive.byu.edu/facpub

Part of the Mechanical Engineering Commons

\section{Original Publication Citation}

LeFevre J., Jerry Bowman W. and Jones M. R., "Numerical Simulation of Convection in Triangular Cavities to Predict Solar Still Performance," Journal of Thermophysics and Heat Transfer, Vol. 27, No. 3, 2013, pp. 482-488. doi:https://doi.org/10.2514/1.T4025 JTHTEO 0887-8722

\section{BYU ScholarsArchive Citation}

LeFevre, Jeremy D.; Bowman, W. Jerry; and Jones, Matthew R., "Numerical Simulation of Convection in Triangular Cavities to Predict Solar Still Performance" (2013). Faculty Publications. 3189.

https://scholarsarchive.byu.edu/facpub/3189 


\section{Numerical Simulation of Convection in Triangular Cavities to Predict Solar Still Performance}

\author{
Jeremy LeFevre* \\ Brigham Young University \\ Fletcher Building 125A \\ Provo, Utah 84602 \\ USA \\ +1 (801) 550-9113 \\ jlefevre76@hotmail.com
}

\author{
W. Jerry Bowman \\ Brigham Young University \\ Crabtree Building 435 \\ Provo, Utah 84602 \\ USA \\ +1 (801) 422-4316 \\ jbowman@et.byu.edu
}

\author{
Matthew R. Jones \\ Brigham Young University \\ Crabtree Building 435 \\ Provo, Utah 84602 \\ USA \\ +1 (801) 422-3070 \\ mrjones@byu.edu
}




\begin{abstract}
In order to improve modeling of solar still behavior, the convection correlations currently used need to be improved upon. Variations in operating parameters and cover geometries make it difficult to use a single correlation to describe the operation of all solar stills. In this work, three right triangles (representing covers at $15^{\circ}, 30^{\circ}$, and $45^{\circ}$ ) were modeled, meshed and solved to predict the convection heat transfer inside for a variety of operating conditions. For a correlation of the form $N u=C \cdot R a^{n}$, it was found that $C=1.0,0.56$, and 0.66 , and $n=0.19,0.24$, and 0.24

for $15^{\circ}, 30^{\circ}$, and $45^{\circ}$ respectively. A grid independence study implied error of up to $37 \%$ for the CFD data (and therefore the correlation). The correlation is useful for Grashof numbers ranging from up $4.0 \times 10^{3}$ to $1.0 \times 10^{9}$ with error up to $37 \%$. The correlation showed some reasonable agreement with Shruti's correlation, and extends the range of Grashof numbers over which an estimate for the Nusselt number can be made. The results here also verify the need for a correlation that accounts for specific cover geometry.
\end{abstract}


Keywords: passive, solar, still, convection, triangle, triangular, cavity

\section{INTRODUCTION AND LITERATURE REVIEW}

Accurately calculating the heat and mass transfer within a solar still is always of interest to designers of solar stills. Without accurate convection correlations, there cannot be accurate predictions of the total distillation (using the heat and mass transfer analogy). The heat and mass transfer analogy can be related using the Lewis number, thermal conductivity, and mass diffusivity. The relationship is given

$$
h_{m}=h \frac{D_{A B} L e^{n}}{k} .
$$

One of the first to study convection in cavities as it relates to solar distillation was Dunkle, who found $\mathrm{C}=0.075$ and $\mathrm{n}=1 / 3$ for a correlation of the form

$$
N u=C \cdot(G r P r)^{n}=C \cdot R a^{n}[1] .
$$

Clark came up with a similar correlation, except he extended the range to cover lower Grashof Numbers and divided the coefficients into laminar and turbulent regions [2]. Shawaqfeh and Farid [3] found a fit with $\mathrm{C}=0.067$ and $\mathrm{n}=1 / 3$, also very similar to Dunkle's results. Kumar and Tiwari used regression to find $\mathrm{C}=0.0322$ and $\mathrm{n}=0.4144$ for Grashof numbers ranging in the millions [4]. Finally, probably the most extensive work for triangular cavities was completed by Shruti and Tiwari, in which coefficients were found for triangular geometries at $15^{\circ}, 30^{\circ}$, and $45^{\circ}$ [5]. Table 2 summarizes coefficients and Grashof ranges for the mentioned works. The characteristic length for these correlations is defined as 


$$
L_{C}=\frac{\forall}{A_{b}}=\frac{H}{2}
$$

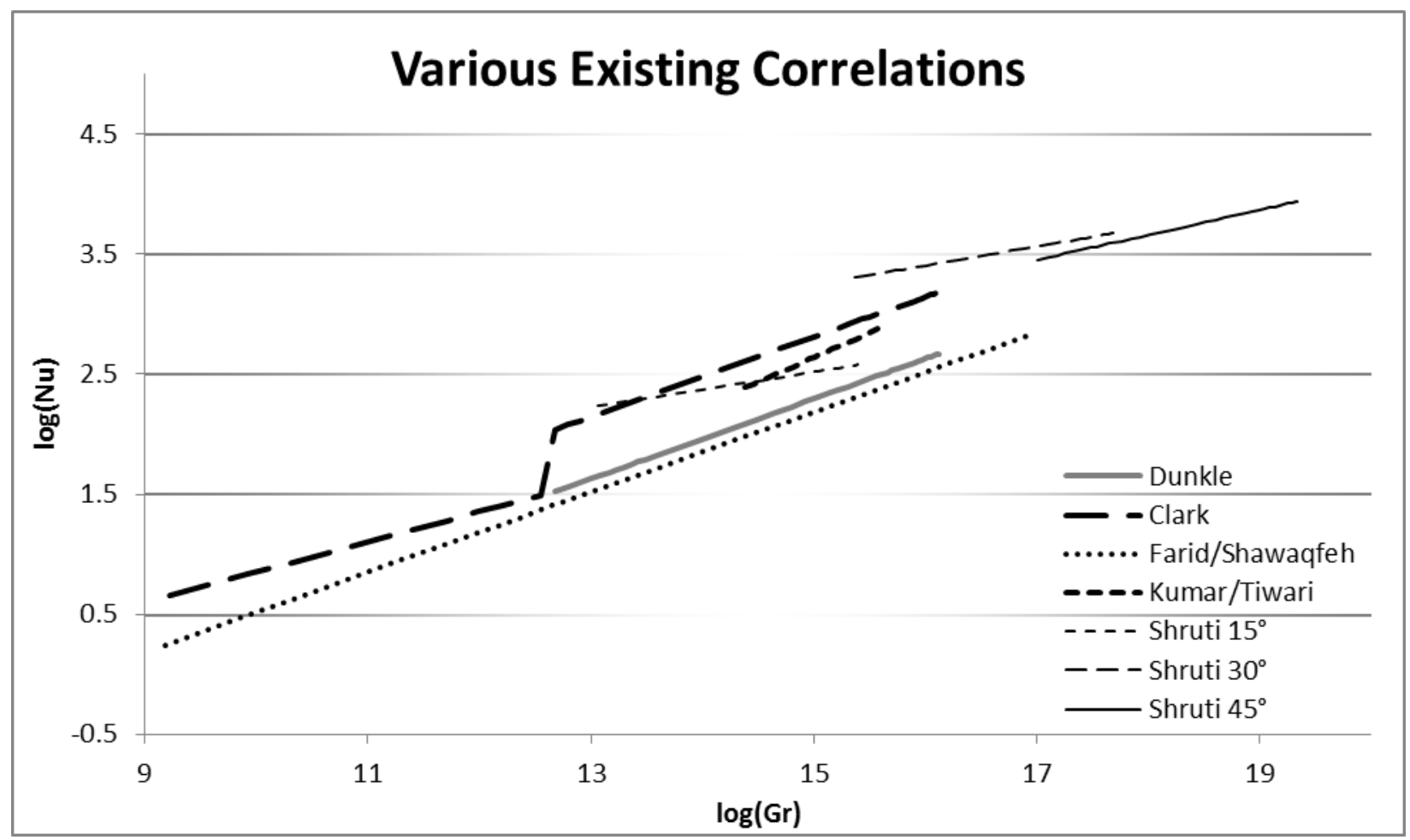

Figure 1: Comparison of Existing Convection Correlations

While there are multiple correlations that have been developed for predicting the convection and mass transfer coefficient, they are not always in good agreement (see Figure 1) and some have limited Grashof number range. For example, Shruti's correlations predict higher Nusselt number at higher Grashof numbers than all the other correlations. On the other hand, Farid and Shawaqfeh predict lower values of Nusselt over a wide range compared to all other correlations. All of the previous correlations were experimentally measured using specific cover geometries, and may be less accurate for cover geometries that are different than the original cover for which they were developed. As a result, it is desirable to develop a correlation that can be used over a wide range of geometries and Grashof numbers. The current approach, like 
Shruti's, will account for changes in cover geometry and extend the range of Grashof numbers compared to earlier correlations. CFD is an obvious choice when data is desired without having to build a prototype or purchase data acquisition hardware.

In the paper that follows, the geometries studied will first be defined. Next, the numerical grid and solution process will be described. Lastly, the results of the simulation will be presented and compared to the correlations presented above.

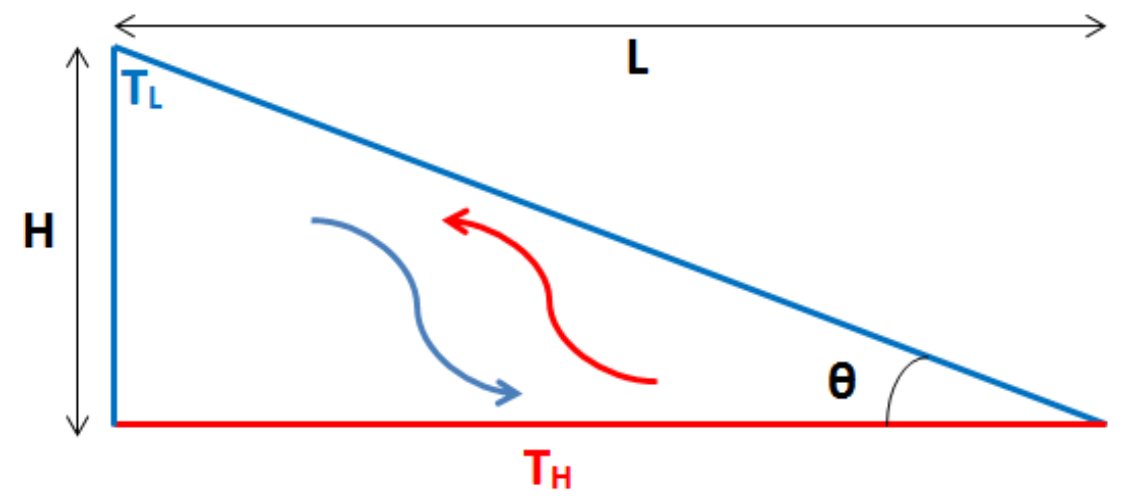

Figure 2: Geometry and Dimensions of Triangular Cavity

\section{GEOMETRIES STUDIED}

The current study modeled right triangle cavities at angles of $15^{\circ}, 30^{\circ}$, and $45^{\circ}$. The reason for studying different geometries is due to changes in the flow with changes in the tilt angle. These changes are due to the fact that the flow is impeded near the sharp corner of the still, where the eddies are inhibited by the meeting of the two walls. As the mentioned 
impediment is reduced by higher angles, the eddies are allowed to constructively interfere with each other and direct the flow upward more easily where they meet.

Isothermal boundary conditions were assumed. However, a small (1e-4 m) adiabatic surface was created to separate the isothermal boundaries and avoid discontinuities at the intersection of the two isothermal boundaries. Dimensions of the cavities were $\mathrm{L}=1 \mathrm{~m}$ and $\mathrm{H}=$ $\tan (\theta) \mathrm{m}$. See Figure 2 for an illustration of the geometry's setup. To minimize calculation time while still maintaining some accuracy to the experimental data, a 2D cavity was chosen.

\section{CFD SETUP AND SIMULATION}

\subsection{Mesh Creation}

Geometries were created and meshed in Gambit version 2.3.16. Five surfaces were created, two representing the two cover surfaces at temperatures of $T_{L}$, one representing the surface of the basin at a temperature of $\mathrm{T}_{\mathrm{H}}$, and two adiabatic regions were added to avoid discontinuities at the corners. During the meshing process, a sizing function was used to scale the node spacing to the order of the shortest lengths near the shortest adiabatic surfaces. The sizing function was tied to those points with a characteristic size $0.0001 \mathrm{~m}$, a maximum size $0.01 \mathrm{~m}$, and a growth rate of 1.15 . Then, the surfaces and fluid were meshed using triangular elements to reduce false diffusion. The mesh was then exported for use in Fluent 12. The $15^{\circ}$ case started at 
2559 nodes, the $30^{\circ}$ case started at 4376 nodes, and the $45^{\circ}$ case started at 7311 nodes. See Figure 3 for an example of the mesh.

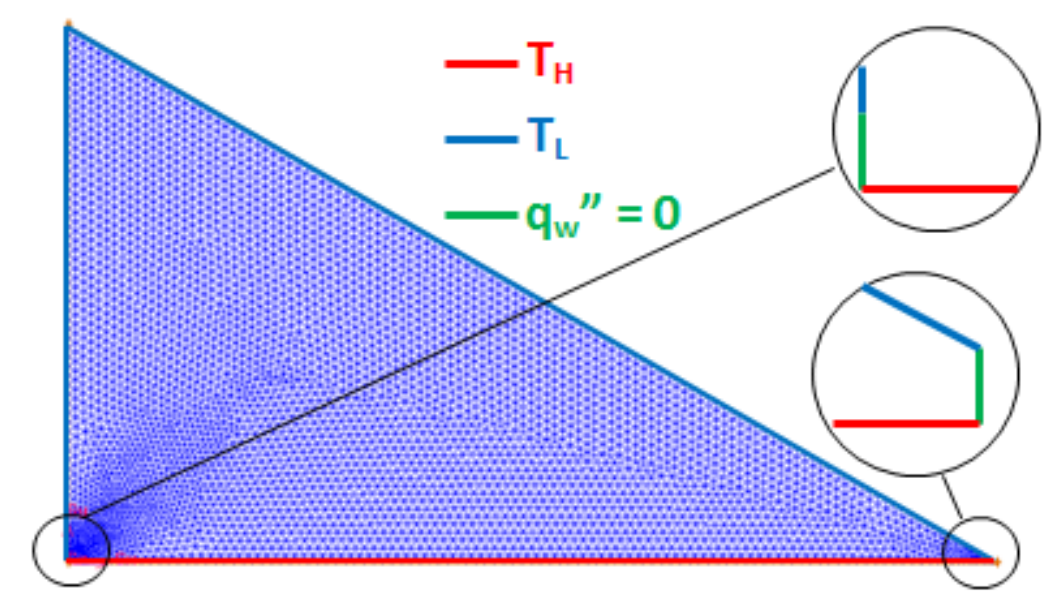

Figure 1: Mesh as Created in Gambit for $30^{\circ}$ Triangle

\subsection{Setup in CFD Package}

As mentioned, Fluent 12 was used to setup and find a solution to the fluid problem. Before running the fluid simulation, the energy equation was used to solve for the case in which heat transfer occurs only via conduction (the effects of gravity were turned off in the model). The total heat transfer was iterated until the surface monitors (heat flux integrated over the various surfaces) converged and the mesh was refined by temperature until grid independence was found. The refined mesh was then used for solving the actual convection cases. The pressure based solver was selected; SIMPLE pressure-velocity coupling was used. To do the convection calculations, gravity was turned on $\left(\mathrm{g}=9.81 \mathrm{~m} / \mathrm{s}^{2}\right)$. The RSM (Reynolds Stress Model) was selected for the calculation of the viscosity, as simulations performed seemed to show the best agreement with existing correlations. $\mathrm{T}_{\mathrm{L}}$ was held constant at $285 \mathrm{~K}$ while $\mathrm{T}_{\mathrm{H}}$ was varied from 
285.01 to $385 \mathrm{~K}$. Running simulations using different temperature differences generated results at different values of Grashof number. Properties were assumed to be close to those of dry air, as they were already in good agreement (less than $2 \%$ error for all properties) with Tiwari's calculation of humid air properties for the film temperature range [6].

$$
\begin{aligned}
T_{\text {film }}= & \frac{T_{H}+T_{L}}{2} \\
k= & 0031+T_{\text {film }} \cdot 7.7 \cdot 10^{-5} \\
c_{p}= & 1161.482-2.368819 \cdot T_{\text {film }}+.01485511 \cdot T_{\text {film }}{ }^{2} \\
& \quad 5.034909 \cdot 10^{-5} \cdot T_{\text {film }}{ }^{3}+9.928569 \cdot 10^{-8} \cdot T_{\text {film }}{ }^{4} \\
& \quad-1.111097 \cdot 10^{-10} \cdot T_{\text {film }}{ }^{5}+6.540196 \cdot 10^{-14} \cdot T_{\text {film }}{ }^{6}
\end{aligned}
$$

Once all the parameters were set, the solution was run for each case and data was collected.

\subsection{Grid Dependence}

As mentioned above, grid independence was found for the conductive heat transfer problem for each geometry, and an example is shown in Figure 4. As can be seen in Figure 4, by about 10,000 nodes, the solution was within $1 \%$ of the grid independent solution. The nearly grid independent meshes were then used to solve the convective problem. Due to limits on time, hardware resources, and software licenses, grid independence was not studied for the convective problem. However, the case where $\theta=30^{\circ}$ and $\Delta \mathrm{T}=1 \mathrm{~K}$ was refined according to velocity and 
turbulent viscosity gradients. The error was estimated by comparing the value of the convective heat transfer for the coarse grids to that of the refined. It was found that up to $37 \%$ error was possible using the coarser grid instead of the refined grid. Figure 5 shows the result of the grid dependence study for the $\theta=30^{\circ}, \Delta \mathrm{T}=1 \mathrm{~K}$ case.

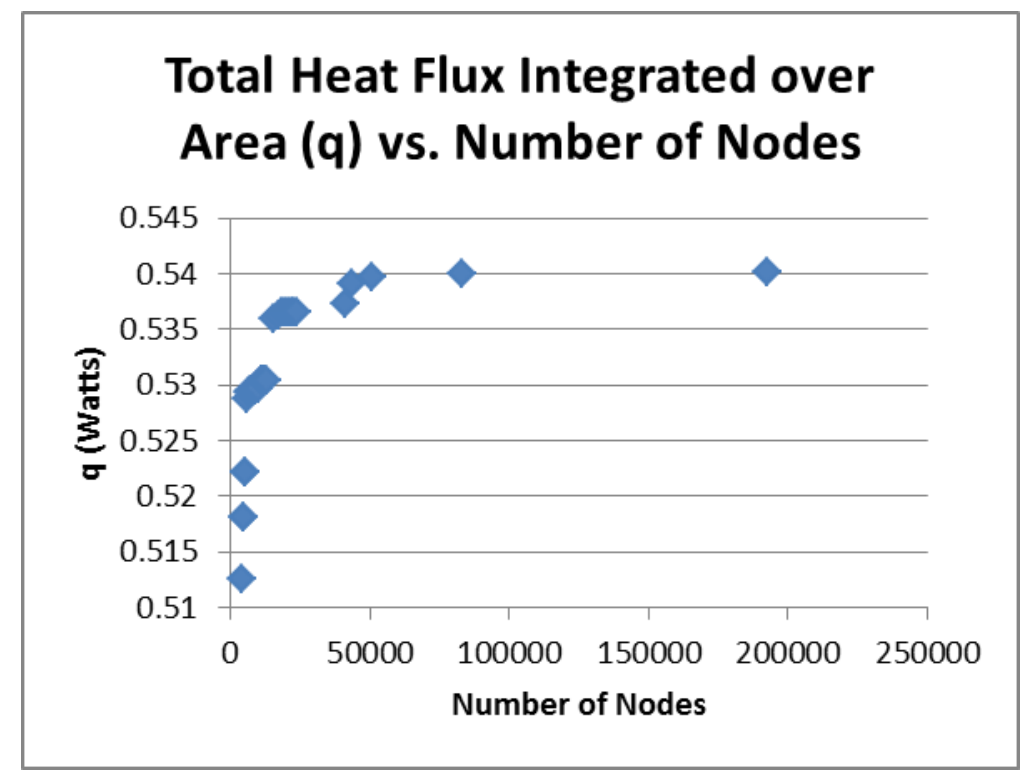

Figure 2: Grid Dependence for Conductive Heat $\operatorname{Transfer}\left(\Delta \mathrm{T}=1 \mathrm{~K}, \boldsymbol{\theta}=30^{\circ}\right)$ 


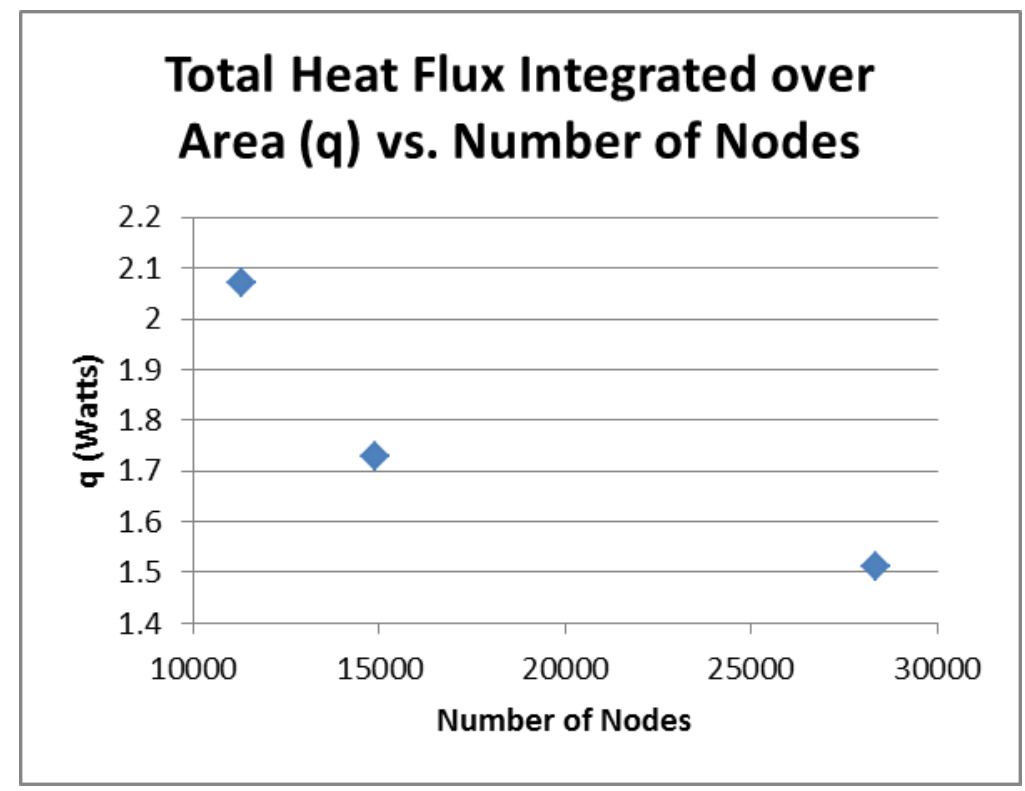

Figure 3: Grid Dependence for Convective Heat Transfer $(\Delta T=1 \mathrm{~K})$

\section{RESULTS}

At the end of the simulations, the data was gathered in a spreadsheet for evaluation. Table 1 and Figure 6 summarize the results. One goal of the research was to extend the range of Grashof numbers over which a correlation was available, so the basin temperature was varied logarithmically as shown in Table 1. Using Shruti's experimental work [7], error and Grashof number ranges were estimated for his varied tilt angle correlation (about 21.1\% error). Similar estimates for Grashof range were made from Farid and Shawaqfeh's article [3]. Figure 7 shows this work's CFD results, nearly paralleling Shruti's model. Figure 8 (for the $30^{\circ}$ tilted cover plate) shows some disagreement between Shruti's correlation and CFD data, but within the 
estimated error bounds. Figure 9 (for the $45^{\circ}$ tilted cover plate) again shows the parallel behavior for Shruti's results and the CFD results given here. Figure 6 shows the general trend where cavities with lower cover tilt angles occupy a space with lower Nusselt numbers. Dunkle's correlation predicts Nusselt numbers approximately 35\% to 55\% lower than the CFD results (Figure 10). Farid's also seems to underestimate the Nusselt numbers (Figure 12). Clark's model (Figure 11) agrees well with the CFD for the higher range of Grashof numbers in the turbulent region. Kumar and Tiwari's model (Figure 13) seems to also occupy a region very near the CFD results. After considering the correlations mentioned, it was found that Shruti's correlations matched the CFD results better than the others (see Figures 7 to 9). Since the other correlations failed to capture the effects of changing the tilt angle, it's logical to assume that Shruti's correlation is the most accurate. The deviation between Shruti's results and the CFD results is still fairly high, but two possibilities could give an explanation: 1 . The actual still covers used to collect experimental data by Shruti were three dimensional and finite, whereas the CFD simulation was for a two dimensional enclosure (which implies an infinite cover). 2. The actual single slope stills constructed by Shruti appear to have been trapezoidal cavities rather than triangular cavities $[5,7]$, which would cause some deviation due to the added gap between the basin and cover. The CFD data presented here was used to generate correlation coefficients which are given in Table 2.

Note that these correlations should mainly be used in solar stills that resemble triangular cavities, as error increases with deviations from the assumed geometry. Further work should be done to find valid correlations for angles greater than $45^{\circ}$ or less than $15^{\circ}$. With further data, the correlation coefficients themselves could be modeled as functions of the tilt angle. 
Table 1: CFD Results

\begin{tabular}{|c|c|c|c|c|c|}
\hline $\mathbf{1 5}^{\circ}$ & & $\mathbf{3 0}^{\circ}$ & & $\mathbf{4 5}^{\circ}$ & \\
\hline $\mathbf{T}_{\text {cover }}(\mathbf{K})$ & $\mathbf{q}$ (Watts) & $\mathbf{T}_{\text {cover }}(\mathbf{K})$ & $\mathbf{q}$ (Watts) & $\mathbf{T}_{\text {cover }}(\mathbf{K})$ & $\mathbf{q}$ (Watts) \\
\hline 285.01 & $9.57 \mathrm{E}-03$ & 285.01 & $6.36 \mathrm{E}-03$ & 285.01 & $6.05 \mathrm{E}-03$ \\
\hline 285.1 & $1.27 \mathrm{E}-01$ & 285.1 & $9.96 \mathrm{E}-02$ & 285.1 & $1.14 \mathrm{E}-01$ \\
\hline 286 & $2.09 \mathrm{E}+00$ & 286 & 1.673 & 286 & $2.13 \mathrm{E}+00$ \\
\hline 295 & $3.32 \mathrm{E}+01$ & 295 & $3.55 \mathrm{E}+01$ & 295 & $3.62 \mathrm{E}+01$ \\
\hline 335 & $2.23 \mathrm{E}+02$ & 335 & $2.23 \mathrm{E}+02$ & 335 & $2.38 \mathrm{E}+02$ \\
\hline 385 & $5.07 \mathrm{E}+02$ & 385 & $5.07 \mathrm{E}+02$ & 385 & $5.43 \mathrm{E}+02$ \\
\hline
\end{tabular}

Table 2: Correlation Coefficients and Details

\begin{tabular}{|c|c|c|c|c|}
\hline Author(s) & Year & C & n & Valid Range \\
\hline Dunkle & 1961 & 0.075 & $1 / 3$ & $3.2 \times 10^{5}<\mathrm{Gr}<10^{7}$ \\
\hline
\end{tabular}




\begin{tabular}{|c|c|c|c|c|}
\hline Clark & 1990 & $\begin{array}{c}0.21 \\
0.1255\end{array}$ & $\begin{array}{l}1 / 4 \\
1 / 3\end{array}$ & $\begin{array}{l}10^{4}<\mathrm{Gr}<2.5 \times 10^{5} \\
2.51 \times 10^{5}<\mathrm{Gr}<10^{7}\end{array}$ \\
\hline Shawaqfeh/Farid & 1995 & 0.067 & $1 / 3$ & $1.6 \times 10^{5}<\mathrm{Gr}<2.2 \times 10^{7}$ (estimated) \\
\hline Kumar/Tiwari & 1996 & .0322 & 0.4144 & $1.794 \times 10^{6}<\mathrm{Gr}<5.724 \times 10^{6}$ \\
\hline Shruti & 1999 & $\begin{array}{l}1.418 \\
2.536 \\
0.968\end{array}$ & $\begin{array}{l}0.148 \\
0.158 \\
0.209\end{array}$ & $\begin{array}{c}\theta=15^{\circ}, 4.7 \times 10^{5}<\mathrm{Gr}<4.8 \times 10^{6} \\
\theta=30^{\circ}, 4.7 \times 10^{6}<\mathrm{Gr}<4.8 \times 10^{7} \\
\theta=45^{\circ}, 2.5 \times 10^{7}<\mathrm{Gr}<2.5 \times 10^{8} \\
\text { (estimated) }\end{array}$ \\
\hline Current Work & 2012 & $\begin{array}{l}1.0 \\
0.56 \\
0.66\end{array}$ & $\begin{array}{l}0.19 \\
0.24 \\
0.24\end{array}$ & $\begin{array}{l}\theta=15^{\circ}, 4.0 \times 10^{3}<\mathrm{Gr}<1.9 \times 10^{7} \\
\theta=30^{\circ}, 4.0 \times 10^{4}<\mathrm{Gr}<1.9 \times 10^{8} \\
\theta=45^{\circ}, 2.1 \times 10^{5}<\mathrm{Gr}<1.0 \times 10^{9}\end{array}$ \\
\hline
\end{tabular}




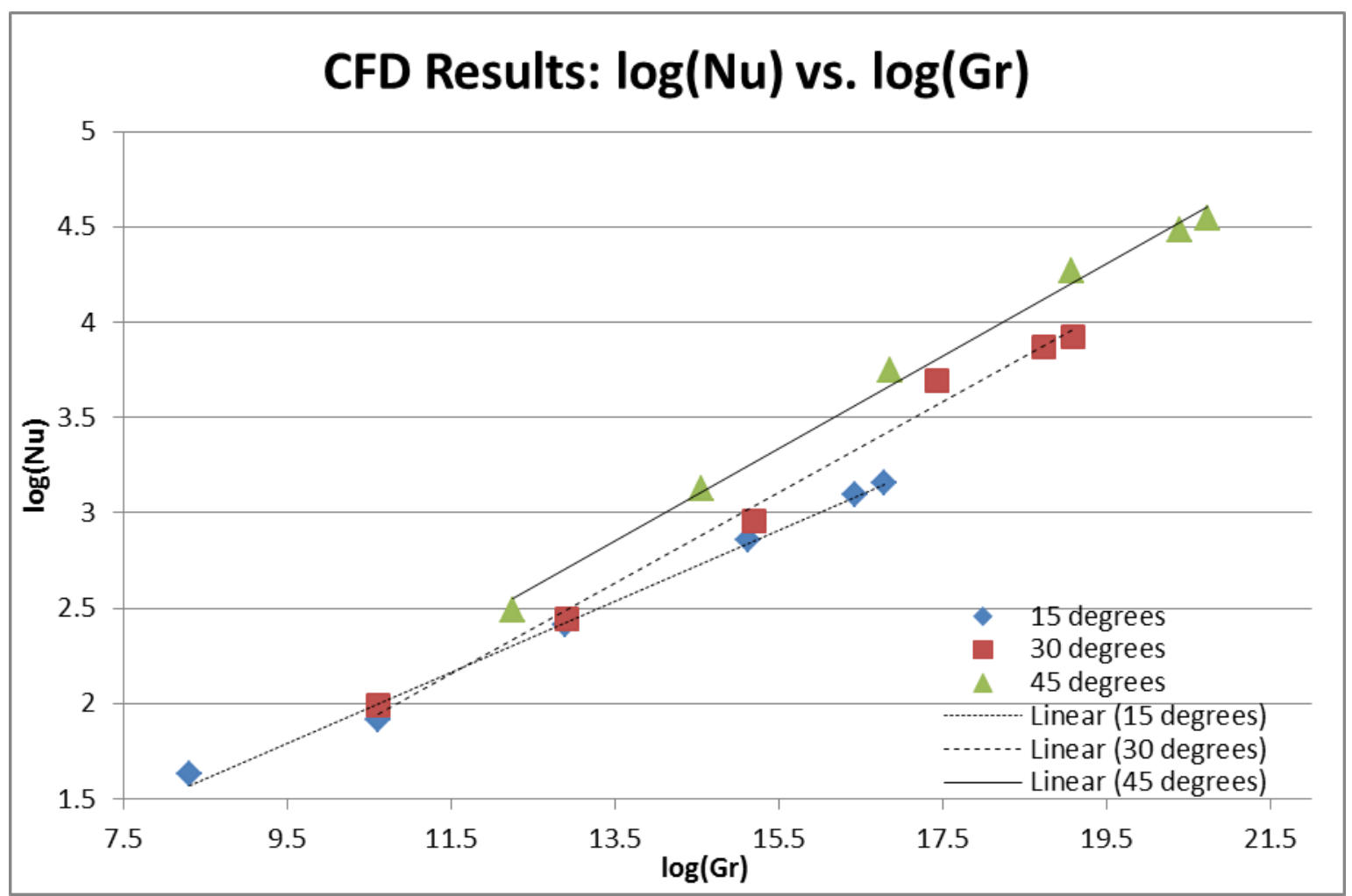

Figure 1: Comparison of CFD Data with Proposed Correlations for $15^{\circ}, 3^{\circ}$, and $45^{\circ}$

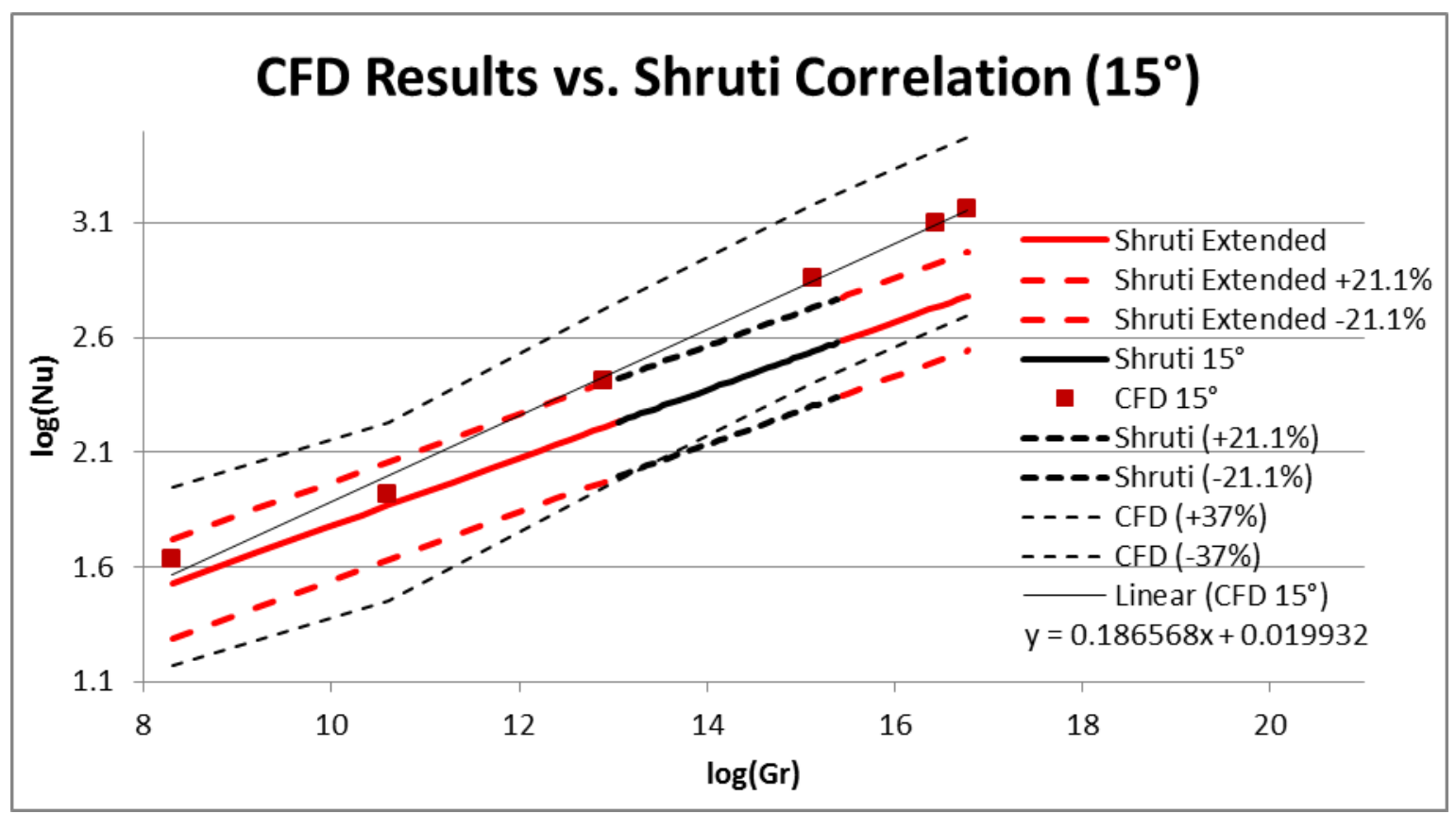

Figure 2: Comparison of Shruti's Correlation with CFD Data $\left(1^{\circ}\right)$ 


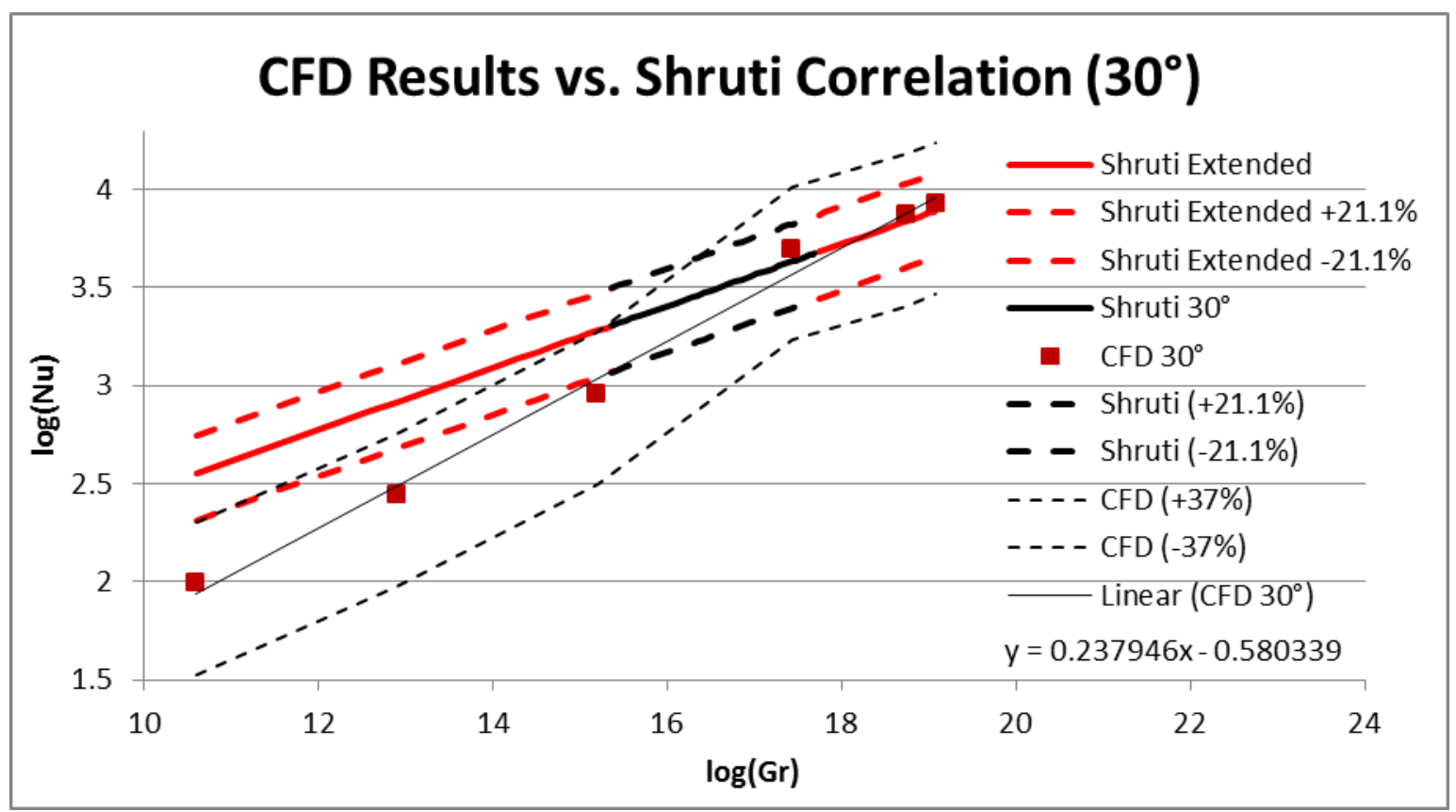

Figure 3: Comparison of Shruti's Model with CFD Data $\left(30^{\circ}\right)$

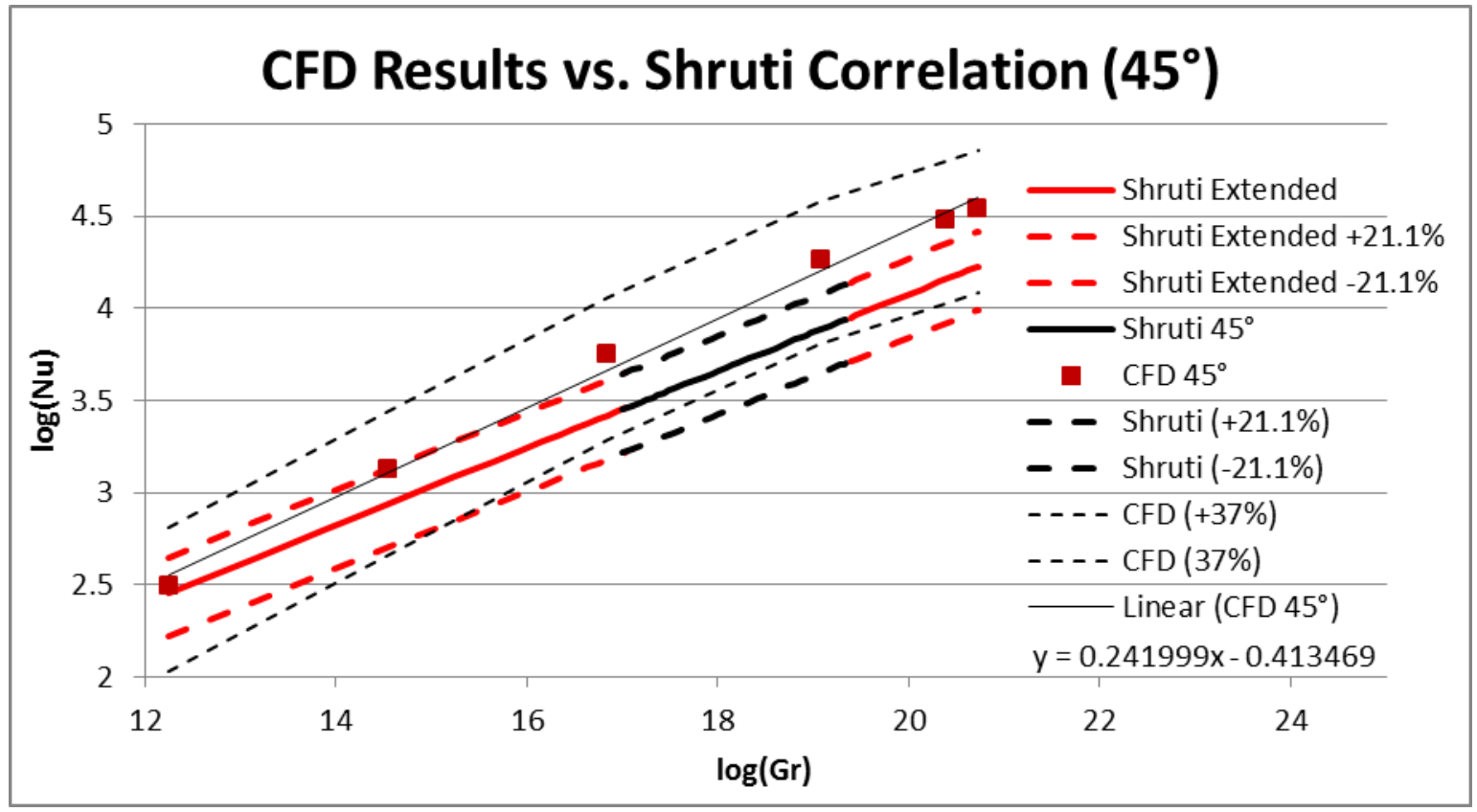

Figure 4: Comparison of Shruti's Correlation with CFD Data $\left(45^{\circ}\right)$ 


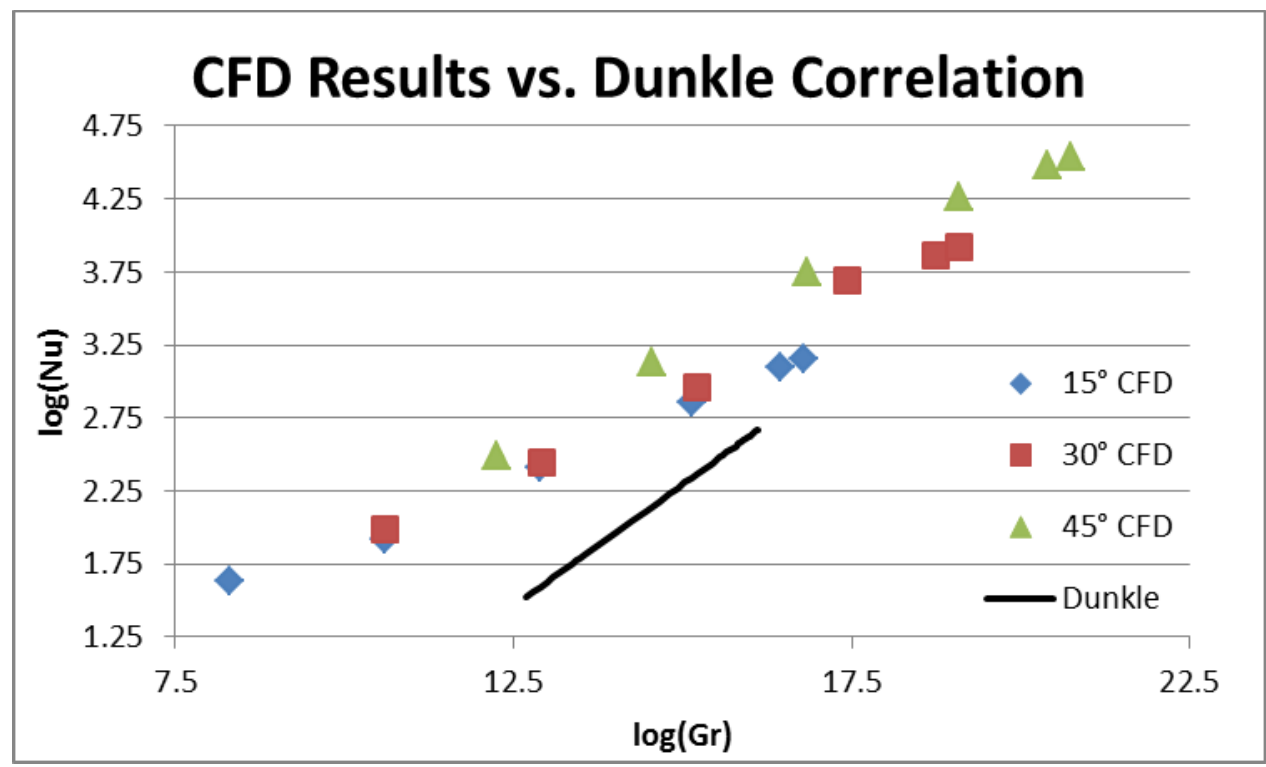

Figure 5: Comparison of Dunkle's Correlation with CFD Data

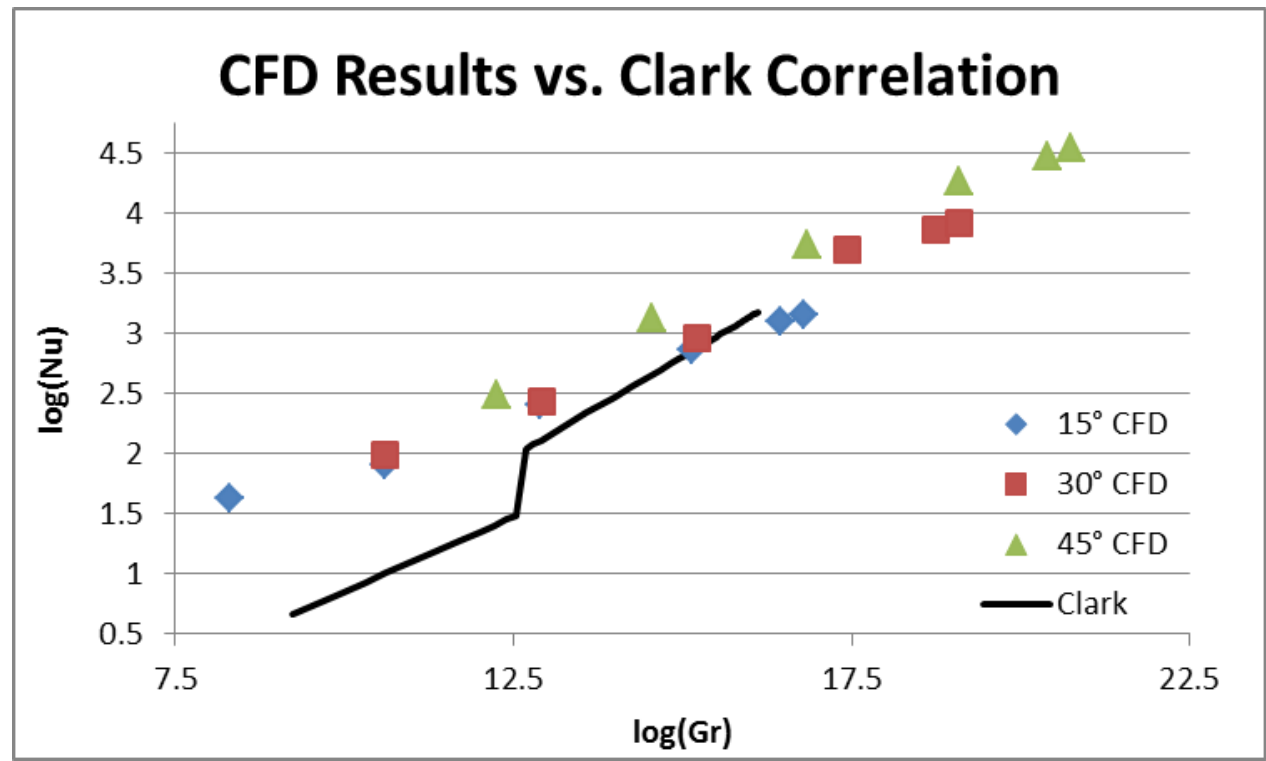

Figure 6: Comparison of Clark's Correlation with CFD Data 


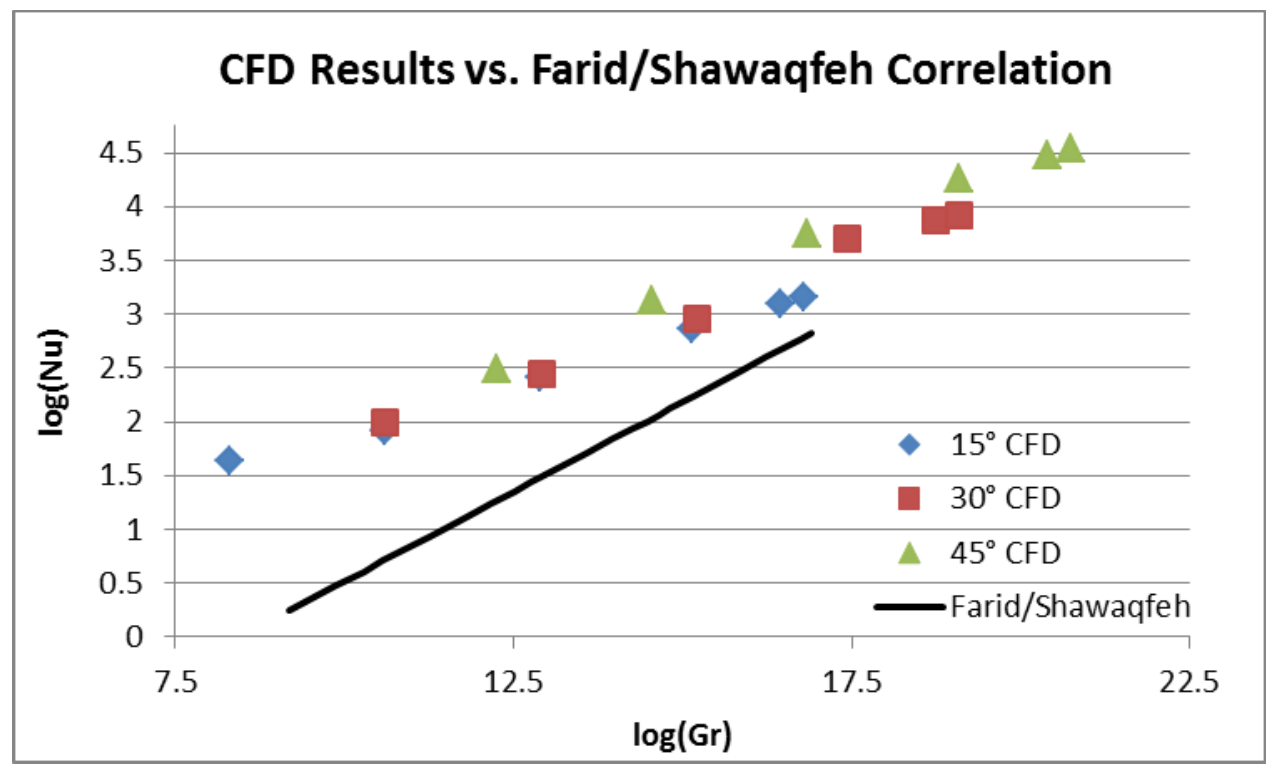

Figure 7: Comparison of Farid/Shawaqfeh's Correlation with CFD Data

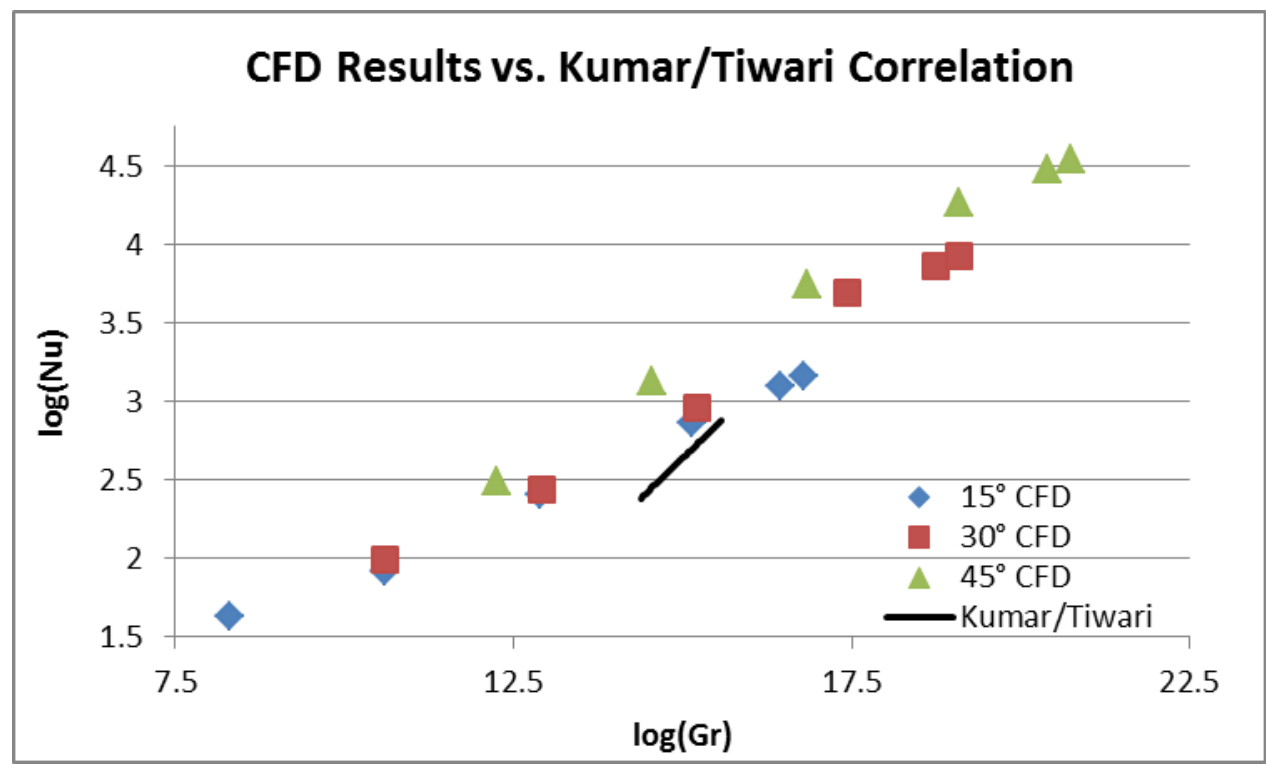

Figure 8: Comparison of Kumar/Tiwari's Correlation with CFD Data 


\section{CONCLUSIONS}

Improving the convection correlations within passive solar stills requires an expansion of the existing correlations to include the specific geometric features of the still. For stills with triangular covers, the current work's correlation is as accurate as Shruti's and can be used over a larger range of Grashof numbers. The correlations presented in this paper can be used for cover geometries with tilt angles ranging from $15^{\circ}$ to $45^{\circ}$ and for Grashof numbers from $4.0 \times 10^{3}$ to $1.0 \times 10^{9}$ (Grashof number range depends on the tilt angle) with less than $37 \%$ error.

Further work could be done to refine the meshes in order to further decrease the error caused by the coarse grids used. Also, the range of angles could be expanded to include lower and higher angles. An increase in access to computing resources might even make it possible to model three dimensional effects and improve the correlations even further. In any case, Shruti's correlation is sufficient for most single slope passive stills and can be appropriately modified to estimate the convection of varied cover angles. The current model can be used with acceptable levels of uncertainty and over a wider range of Grashof numbers. 


\section{REFERENCES}

[1] Dunkle, R.V. (1961). "Solar Water Distilllation: The Roof Type Still and a Multiple Effect Diffusion Still." International Developments in Heat Transfer, A.S.M.E., Proceedings of International Heat Transfer, Part V, 895. (content as cited in Tiwari.)

[2] Clark, J.A. (1990). “The Steady-state Performance of a Solar Still.” Journal of Solar Energy. 44(1): 43. (content as cited in Tiwari.)

[3] Shawaqfeh, A.T. and Farid, M.M. (1995). "New Development in the Theory of Heat and Mass Transfer in Solar Stills.” Solar Energy. 55: 527.

[4] Kumar, S., Tiwari, G.N. and Singh, H.N. (1996). "Estimation of Convective Mass Transfer in Solar Distillation System.” Journal of Solar Energy. 57: 459. (content as cited in Tiwari.)

[5] Shruti, A. (1999). "Computer Based Thermal Modeling of an Advanced Solar Distillation System: An Experimental Study." Diss. IIT Delhi, New Delhi. (content as cited in Tiwari.)

[6] Tiwari, G.N. and Tiwari, A.K. (2008). Solar Distillation Practice for Water Desalination Systems. Kent: Anshan Limited. 37, 43-51, 160, 168, 182-202. Print.

[7] Shruti, A. and Tiwari, G.N. (1998). "Convective Mass Transfer in Double Condensing Chamber and Conventional Solar Still.” Desalination. 115: 181. 
Figure 1: Comparison of Existing Convection Correlations

Figure 2: Geometry and Dimensions of Triangular Cavity

Figure 3: Mesh as Created in Gambit for $30^{\circ}$ Triangle

Figure 4: Grid Dependence for Conductive Heat $\operatorname{Transfer}\left(\Delta \mathrm{T}=1 \mathrm{~K}, \theta=30^{\circ}\right)$

Figure 5: Grid Dependence for Convective Heat Transfer $(\Delta \mathrm{T}=1 \mathrm{~K})$

Figure 6: Comparison of CFD Data with Proposed Correlations for $15^{\circ}, 30^{\circ}$, and $45^{\circ}$

Figure 7: Comparison of Shruti's Correlation with CFD Data $\left(15^{\circ}\right)$

Figure 8: Comparison of Shruti's Model with CFD Data $\left(30^{\circ}\right)$

Figure 9: Comparison of Shruti's Correlation with CFD Data $\left(45^{\circ}\right)$

Figure 10: Comparison of Dunkle's Correlation with CFD Data

Figure 11: Comparison of Clark's Correlation with CFD Data

Figure 12: Comparison of Farid/Shawaqfeh's Correlation with CFD Data

Figure 13: Comparison of Kumar/Tiwari's Correlation with CFD Data

Table 1: CFD Results

Table 2: Correlation Coefficients and Details 